\title{
Greater exposure of nearshore habitats in the Bering Sea makes fish early life stages vulnerable to climate change
}

\author{
Lorenzo Ciannelli ${ }^{1, *}$, Ericka Smith ${ }^{2}$, Kelly Kearney ${ }^{3,4}$, Mary Hunsicker $^{5}$, \\ Carey McGilliard ${ }^{4}$
}

\author{
${ }^{1}$ College of Earth, Ocean, and Atmospheric Sciences, Oregon State University, Corvallis, OR 97330, USA \\ ${ }^{2}$ Department of Statistics, Oregon State University, Corvallis, OR 97330, USA \\ ${ }^{3}$ University of Washington, Cooperative Institute for Climate, Ocean, and Ecosystem Studies, Seattle, WA 98195, USA \\ ${ }^{4}$ National Oceanic and Atmospheric Administration, Alaska Fisheries Science Center, Seattle, WA 98115, USA \\ ${ }^{5}$ Fish Ecology Division, National Oceanic and Atmospheric Administration, National Marine Fisheries Service, Newport,
} OR 97365, USA

\begin{abstract}
Marine fish species with complex life cycles undergo ontogenetic changes in their physiological and habitat requirements. Therefore, predicting how warming ocean conditions are likely to impact fish populations requires size-(age-) and habitat-specific analyses. We determined the habitat exposure and scope of adaptability of 4 shelf-oriented flatfish species in the Bering Sea to projected climate-driven warming. We quantified present day and end-of-century habitat exposure based on hindcasts and forecasts of regional ocean circulation models and quantified fish adaptability based on changes in depth distribution and from published thermal tolerances of northern rock sole Lepidopsetta polyxystra, yellowfin sole Limanda aspera, Alaska plaice Pleuronectes quadrituberculatus, and flathead sole Hippoglossoides elassodon. These 4 species complete their life cycle within the Bering Sea shelf but have different depth preferences and thermal tolerances throughout ontogeny. We found that species or size ranges that occupy the inner shelf, such as northern rock sole, yellowfin sole, and Alaska plaice, are exposed to higher seasonal variability compared to outer shelf species. While these inner shelf species are likely adapted to large seasonal changes in temperature, the future range of seasonal variability was projected to exceed their thermal tolerances. Therefore, we expect species that reside inshore during part of their life cycle and have high temperature sensitivity and limited mobility to be particularly vulnerable to climate change.
\end{abstract}

KEY WORDS: Habitat exposure $\cdot$ Climate change $\cdot$ Flatfish $\cdot$ Bering Sea $\cdot$ Vulnerability $\cdot$ Ontogeny

\section{INTRODUCTION}

Marine fish species with complex life cycles undergo ontogenetic changes in their physiological and habitat requirements (Bartolino et al. 2011). Typically, settled individuals of many shelf or slopeoriented species move from shallow to deep habitats as they age, and coastal and shallow regions are im-

${ }^{*}$ Corresponding author: lorenzo.ciannelli@oregonstate.edu portant nursery habitats during juvenile stages (Gibson et al. 2002, Ryer et al. 2010). Therefore, modeling species-environment relationships and predicting how warming ocean conditions are likely to impact fish populations requires size-(age-) (e.g. Barbeaux \& Hollowed 2018) and habitat-specific analyses.

During early life stages, fish are limited in their ability to move away from unfavorable conditions,

(1) L. Ciannelli, E. Smith and outside the USA, The U.S. Government 2022. Open Access under Creative Commons by Attribution Licence. Use, distribution and reproduction are unrestricted. Authors and original publication must be credited.

Publisher: Inter-Research · www.int-res.com 
making them more vulnerable to extreme environmental changes (Llopiz et al. 2014, Dahlke et al. 2020). In addition, the exposure of different fish habitats to environmental change varies greatly within the same ecosystem. While nearshore fish species may be adapted to large seasonal shifts in water temperature, the projected variability may exceed the thermal window that these species can tolerate, particularly for stenothermic species of Arctic and subArctic origins (Mueter \& Litzow 2008).

In this study, we determined the vulnerability of 4 shelf-oriented flatfish species in the Bering Sea (BS). Species vulnerability to climate change is influenced by both exposure to different levels of (or variations in) environmental parameters (e.g. temperature) and sensitivity to such exposure (IPCC 2014). Sensitivity is, in turn, a function of adaptive reactions, which include behavioral (such as changes in distribution), physiological (such as acclimation), and microevolutionary responses (Donelson et al. 2019). Here, we focused the sensitivity assessment of behavioral responses by determining the degree to which species change their depth distribution in relation to changes in temperature. We quantified current and future (end of century) habitat exposure based on hindcast and forecast of ocean circulation models tested for the region.

We focused our study on flatfish species that complete their life cycle on the shelf $(<200 \mathrm{~m}$ depth) but have varying degrees of distribution and exhibit habitat changes throughout ontogeny: northern rock sole Lepidopsetta polyxystra, which completes its life cycle in the eastern and warmer portion of the BS inner shelf; yellowfin sole Limanda aspera, which has pronounced ontogenetic and seasonal migrations between the western and coldest position of the inner and outer shelf (Wilderbuer et al. 1992); Alaska plaice Pleuronectes quadrituberculatus, which completes its life cycle in the inner and middle central portion of the shelf; and flathead sole Hippoglossoides elassodon, which is an outer shelf species.

In the BS, seasonal and interannual variability in the temperatures of the bottom waters that all 4 of these flatfish species inhabit are tightly coupled to variability in sea ice extent and timing (Stabeno et al. 2001). In the future, bottom temperatures may experience changes in variability due to the effects of climate change on sea ice dynamics. The 4 focal species are relatively less studied compared to other larger and commercially important flatfish species (e.g. Pacific halibut, arrowtooth flounder) and have restricted depth preferences and specialized diets which may limit the ability of individuals to shift their depth dis- tribution (Swartzman et al. 1992, McConnaughey \& Smith 2000). Additionally, these species are known to use different habitats from early to adult stages and are, therefore, likely to experience different amounts of variation in environmental conditions during their life cycle (Wilderbuer et al. 1992, Porter \& Ciannelli 2018, Nichol et al. 2019). While our analyses focused on the BS, the assessment of species climate vulnerability is germane to many coastal marine systems that are experiencing progressive warming (Holsman et al. 2017).

\section{MATERIALS AND METHODS}

The study area included the eastern BS shelf, delimited by the date line to the west and the Alaska Peninsula to the east, and the 30 and $200 \mathrm{~m}$ isobaths to the north and south (see Fig. 1). During summer, the eastern BS shelf can be separated into 3 oceanographic domains: (1) the inner shelf, with depth $<50 \mathrm{~m}$ and mixed water column; (2) the middle shelf, between 50-100 m depth, characterized by 2 surface fronts, cold bottom temperature, and progressive water column stratification; and (3) the outer shelf, between 100-200 m depth, with stratified water column and influx of bottom warm water from the slope and BS basin. During summer, much of the middle shelf is characterized by a frigid water mass, the cold pool, formed as a result of the previous winter sea ice formation and onset of summer water stratification (Stabeno et al. 2012).

We used catch per unit effort (CPUE), depth, and bottom water temperature data from the National Marine Fisheries Service BS summer bottom trawl surveys from 2000-2018 (Stevenson \& Lauth 2019). We chose to focus the analyses on these 2 decades because they include stanzas of warm and cold years and encompass the most extreme variation in bottom water temperatures on the BS shelf (Stabeno et al. 2017). Further, this period includes the most reliable and extensive collection of fish length data.

Survey start dates ranged from 24 May-12 June over the history of the survey (1982-present), and end dates ranged from 12 July-11 September; the mean (across stations) standard deviation (across years) in sampling date at any specific station in the primary survey polygon was $6.61 \mathrm{~d}$ over this period. Bottom temperatures in the middle and outer shelf regions were very stable across these time periods due to strong stratification. Bottom temperatures in the inner domain can vary more widely across these time scales due to surface heating, but interannual 
variability still tended to be higher than within-year variability during the sampling period (see Kearney 2021 for details). For most years, the spatial extent of the survey spanned from the Alaska Peninsula to approximately $61^{\circ} \mathrm{N}$, and the depths at trawl stations ranged from 30-192 m (see Fig. 1). In 2010 and 2017, the survey expanded into the northern BS shelf; however, we excluded this area from our analysis.

We used measurements from the survey to quantify average temperatures and coefficients of variation (CVs) (Table 1). However, given the 2 mo duration of the survey, these measurements are not synoptic and may compound spatial and temporal variability of the bottom temperature on the shelf. Therefore, regional model output was used in place of the survey temperatures to quantify habitat exposure. Survey temperatures were used to classify years as warm or cold based on whether the summer average temperature of the middle shelf (50-100 m depth) was above or below the reference average from 2000-2018 (Table 1). Identification of extreme marine heatwave years was based on Carvalho et al. (2021).

We used a high-resolution regional ocean model to quantify bottom temperature magnitude, range, and variability (i.e. habitat exposure) for the southeastern shelf region across both seasonal and interannual periods. The model, known as Bering10K, is an implementation of the Regional Ocean Modeling System (ROMS), a free-surface, primitive equation hydrographic model (Shchepetkin \& McWilliams 2005, Haidvogel et al. 2008). Its domain spans the BS and northern Gulf of Alaska with $10 \mathrm{~km}$ horizontal resolution and 30 terrain-following depth levels. Bering10K has demonstrated high skill in capturing spatiotemporal variability in bottom temperature across the BS region (Kearney et al. 2020, Kearney 2021).

We applied our exposure analysis to 2 sets of Bering10K simulations. The first was a hindcast simulation driven by reanalysis-based atmospheric and lateral ocean boundary conditions (see Kearney et al. 2020 for full details). The full simulation spans 1970-2021; we limited our analysis to the period of 1990-2020, which encompasses typical decadal temperature variability and overlaps with the groundfish survey data. We also looked at a long-term multimodel forecast driven by global-scale models from the sixth phase of the Climate Model Intercomparison Project (CMIP6). Three specific parent models (MIROC ES2L, CESM2, and GFDL ESM4) were chosen because they encompass the envelope of variability in long-term trends within the larger CMIP6 suite. The CMIP6 global earth system models themselves do not fully capture biophysically relevant features, such as the formation of $<2^{\circ} \mathrm{C}$ bottom water on the shelf, due to their coarse horizontal resolution $\left(1^{\circ}\right)$ (see Kearney et al. 2020 for more details). Dynamically downscaling (i.e. driving a highresolution regional ocean model using atmospheric and lateral ocean boundary condition data from the CMIP6 models) allows us to simulate important regional-scale processes with higher resolution while preserving the larger-scale climate state predicted by the global models. Unfortunately, we were unable to downscale the entire CMIP6 suite due to computational and data storage limitations, hence the choice of specific ensemble members from within the larger collection to represent the uncertainty envelope.

We quantified variability for 3 periods within these forecasts: current (1985-2015), mid-century (20352065), and end-of-century (2070-2100). While it is somewhat redundant to show results for both the hindcast simulation and the historical periods of the forecasts, we chose to do so because the hindcast simulation is driven by a data-assimilating reanalysis and therefore can be used for direct interannual comparison. Also, the global climate model data were not bias-corrected or otherwise adjusted to observations for these particular downscaling simulations. Therefore, the 1990-2020 portion of each climate model projection includes any biases or other mismatches that are present in these parent models. With respect

Table 1. Average temperature and standard deviation of the Bering Sea middle shelf (50-100 m). Note that 2016 and 2018 were extreme marine heatwave years

\begin{tabular}{|cccc|}
\hline Year & $\begin{array}{c}\text { Average } \\
\text { temperature }\left({ }^{\circ} \mathrm{C}\right)\end{array}$ & $\begin{array}{c}\text { Standard } \\
\text { deviation }\left({ }^{\circ} \mathrm{C}\right)\end{array}$ & Category \\
\hline 2000 & 1.477 & 1.249 & Cold \\
2001 & 2.031 & 1.760 & Warm \\
2002 & 2.561 & 1.296 & Warm \\
2003 & 3.203 & 1.380 & Warm \\
2004 & 2.502 & 1.566 & Warm \\
2005 & 2.275 & 2.123 & Warm \\
2006 & 0.975 & 2.048 & Cold \\
2007 & 0.713 & 1.516 & Cold \\
2008 & 0.679 & 1.572 & Cold \\
2009 & 0.536 & 1.822 & Cold \\
2010 & 0.383 & 1.807 & Cold \\
2011 & 2.000 & 1.911 & Warm \\
2012 & 0.208 & 1.506 & Cold \\
2013 & 0.561 & 1.541 & Cold \\
2014 & 2.384 & 1.810 & Warm \\
2015 & 2.481 & 2.321 & Warm \\
2016 & 3.716 & 2.058 & Warm \\
2017 & 1.434 & 1.895 & Cold \\
2018 & 3.798 & 0.974 & Warm \\
Overall average temperature: $1.743^{\circ} \mathrm{C}$ & \\
& & & \\
\hline
\end{tabular}


to BS bottom temperature, these mismatches are small but not negligible. When comparing the downscaled earth system model-forced historical simulations to the reanalysis-forced hindcast, the GFDL and MIROC bottom temperatures showed a small cool bias across the eastern BS shelf region while the CESM bottom temperatures were biased a bit warm. The mid-century and end-of-century changes were therefore assessed relative to their respective historical time period values rather than using the hindcast values as a baseline.

Variability was measured via the following yearly bottom temperature metrics, calculated for each individual $10 \mathrm{~km}$ grid cell for months between May and October (when juvenile flatfish stages are settled in their nursery areas): (1) monthly mean temperature: mean temperature for dates falling within each month; (2) maximum weekly mean temperature: max.

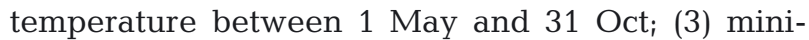
mum weekly mean temperature: min. temperature between 1 May and $31 \mathrm{Oct}_{\text {; }}$ (4) temperature range (maximum - minimum): difference between 2 and 3 .

For each metric, we calculated the climatological mean across each 30 yr period and the $C V$, defined as the standard deviation of the metric across the $30 \mathrm{yr}$ period divided by the climatological mean (in $\mathrm{K}$ ). Calculations were applied to weekly averaged output. The forecast metrics were then averaged across the 3 parent models to acquire a single multi-model forecast value. The 8 metrics (4 means and corresponding CVs) were used to define magnitude, range, and respective variation of bottom temperature at each ROMS grid location, and allowed us to differentiate between interannual and seasonal temperature variability. Specifically, the temperature range defines locations with the greatest seasonal temperature variability, while the corresponding interannual $\mathrm{CV}$ defines locations with the greatest interannual variability.

To quantify species adaptability, we assessed changes in distribution and temperature exposure using length and abundance data from the trawl survey. Length data represent a subsample of the haul. The proportion of individuals of a given sex and length in the subsample was multiplied by the number of fish of that species in the haul to provide an estimate of the total number of fish by length and sex in each haul. For each species, we quantified the weighted (by CPUE) mean depth and temperature (from survey) across 8 length quantiles. The estimated means and variability for each length quantile are shown as boxplots to compare cold:warm years and cold years:extreme marine heatwave years
(Table 1). Size-specific image plots of individual density in relation to either bottom temperature or depth of occupancy were calculated using 2-dimensional kernel density smoothing and are plotted against length values for each species, comparing warm and cold groupings using scaled-up length as a continuous variable (i.e. no binning).

\section{RESULTS}

\subsection{Metrics of habitat exposure using the Bering10K model}

During the period 1990-2020, the simulated mean summer (July) bottom temperature of the BS shelf reproduced the known signature for the area, with a cold water mass in the middle shelf ranging from -1.8 to $3.0^{\circ} \mathrm{C}$ enclosed between warmer water masses in the inner and outer shelf ranging from 3.0-12.0 and $3.0-6.0^{\circ} \mathrm{C}$, respectively (Fig. 1). The spatial patterns of mean bottom temperature and variation from survey data corroborated the patterns in the ROMS model hindcast simulations during the summer months (see Fig. S1 in the Supplement at www.int-res.com/ articles/suppl/m684p091_supp.pdf). This spatial temperature signature was replicated through MayOctober, albeit with variation in the temperature values (Fig. S2).

The interannual CVs of mean July temperatures were highest in the shallow inner and north portions of the shelf and lowest along the deep outer shelf and the northwesternmost portion of the inner and middle shelf (Fig. 1). In August and September, peaks of temperature variation occur offshore, toward the middle shelf. The seasonal May through October average range of bottom temperatures is highest in the northeast inner shelf, where it reaches values of $10-11^{\circ} \mathrm{C}$ and where the maximum seasonal bottom temperature can reach $13^{\circ} \mathrm{C}$. In contrast, the MayOctober temperature range was less than $3^{\circ} \mathrm{C}$ in the outer shelf region, denoting a lower exposure of these habitats to seasonal temperature variations (Fig. S2). However, the interannual CV of temperature range was higher in the outer shelf than in the inner shelf, indicating that despite lower seasonal variability, deeper habitats are exposed to high interannual variability of bottom temperature (Fig. S2).

The medium (2035-2065) and long-term (20702100) forecasts of bottom temperature predict a warmer BS shelf due to an increase of both MayOct minimum and maximum temperatures throughout the 3 domains (inner, middle, and outer shelf; 

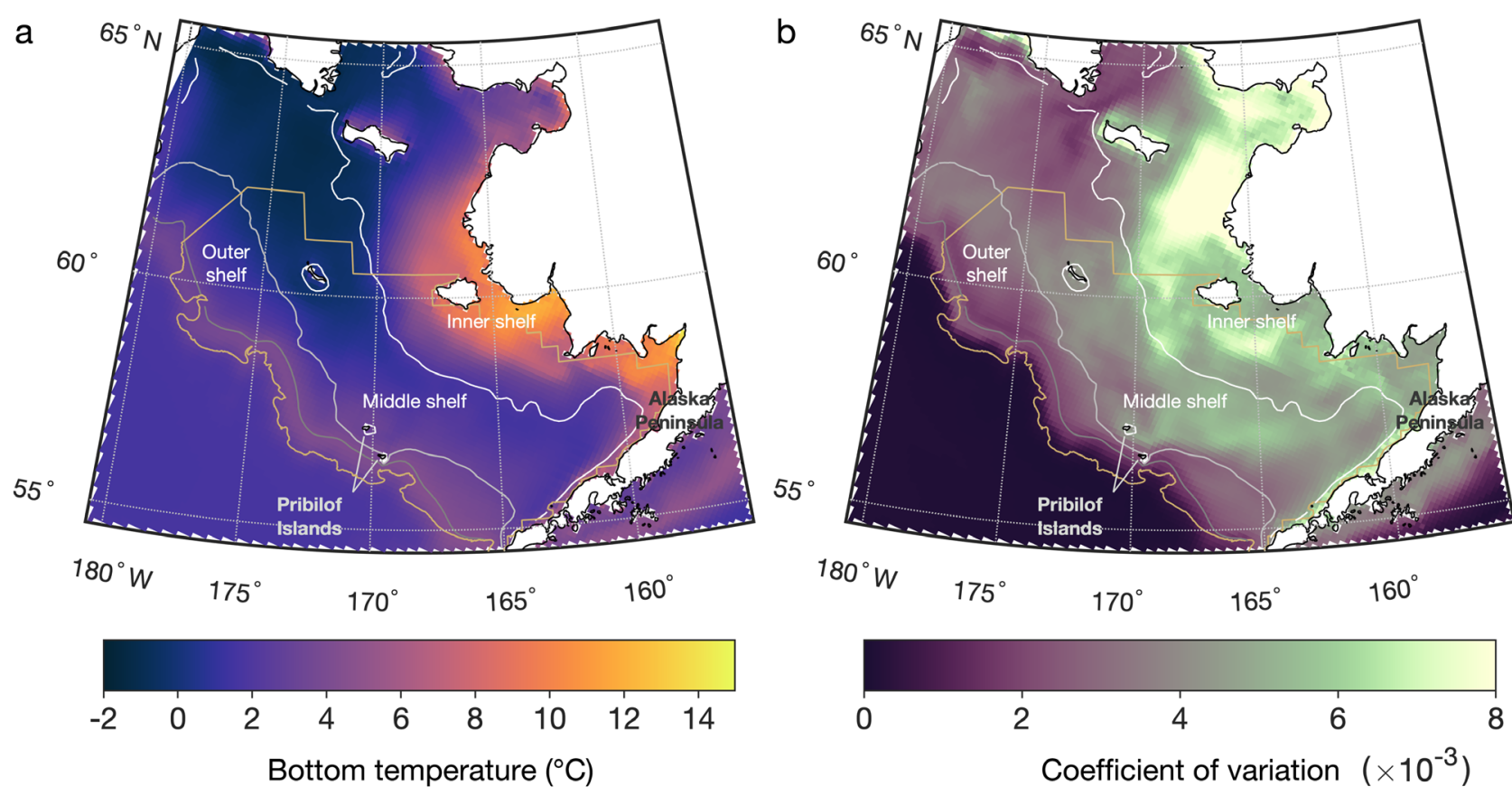

Fig. 1. July bottom temperature (a) mean and (b) coefficient of variation across the eastern Bering Sea shelf region. Depicted values reflect the Regional Ocean Modeling System Bering10K hindcast simulation for the years 1990-2020. Gray lines: 50 m (white), $100 \mathrm{~m}$ (light gray), and $200 \mathrm{~m}$ (medium gray) model isobaths; tan outline: survey sampling polygon

Figs. S3 \& S4). During the historical record (19902020), the model predicts an average of $0.32{\mathrm{wk} \mathrm{yr}^{-1}}^{-1}$ when the bottom temperature of the inner shelf reaches values of $12-13^{\circ} \mathrm{C}$. For the inner shelf, the forecast models predict an increase of between 0.36 (GFDL) and 5.96 (CESM) wk $\mathrm{yr}^{-1}$ of temperatures over $13^{\circ} \mathrm{C}$ by the end of the century relative to the current reference period. Temperatures in the middle and outer shelf are also expected to increase by $3-4^{\circ} \mathrm{C}$, but their maximum values will continue to be lower compared to the inner shelf (Figs. S3 \& S4).

\subsection{Ontogenetic patterns of species distributions and exposure}

The distribution of rock sole (Fig. 2) is concentrated in the northeast reach of the surveyed area. As they age and grow, they occur in deeper areas of the eastern shelf, with the exception of the largest individuals concentrated in shallower areas. An isolated and stable cluster of abundance is localized around the Pribilof Islands, in the outer shelf. Rock sole average depth distribution was around $40 \mathrm{~m}$ for the youngest and smallest individuals captured in the survey $(40-150 \mathrm{~mm}$ ) and gradually increased to $50-60 \mathrm{~m}$ in larger individuals, with the largest individuals examined moving back to shallower waters. These depth distribution patterns did not change between cold and warm years. In these habitats, the fish are exposed to temperature variations averaging $2.5^{\circ} \mathrm{C}$, especially during early life stages (Fig. 2).

Yellowfin sole (Fig. 3) is also an inner-middle shelf species. During early and smaller life stages, these fish are almost exclusively found in the cold and northwestern portion of the sampled region. As they grow, they occur in the deeper areas of the middle shelf and the variability around the mean depth distribution increases, as underscored by the expansion of spatial occupancy of intermediate and larger individuals. Their average depth distribution was concentrated around $30-35 \mathrm{~m}$ for the youngest and smallest individuals examined $(20-180 \mathrm{~mm})$ and reached a maximum of $45-50 \mathrm{~m}$ at intermediate and larger size ranges. Noticeably, the variability around the mean depth distribution increased with size, as highlighted by the expansion of spatial occupancy of intermediate and larger individuals. These depth distribution patterns did not change between cold and warm years, and the average range of temperature exposure between warm and cold years varied by about $1.5-2.0^{\circ} \mathrm{C}$ (Fig. 3).

Alaska plaice has a distinctive middle shelf distribution throughout most of its life cycle (Fig. 4). Only the smaller and younger life stages are found on the inner shelf. Their average depth distribution ranged 

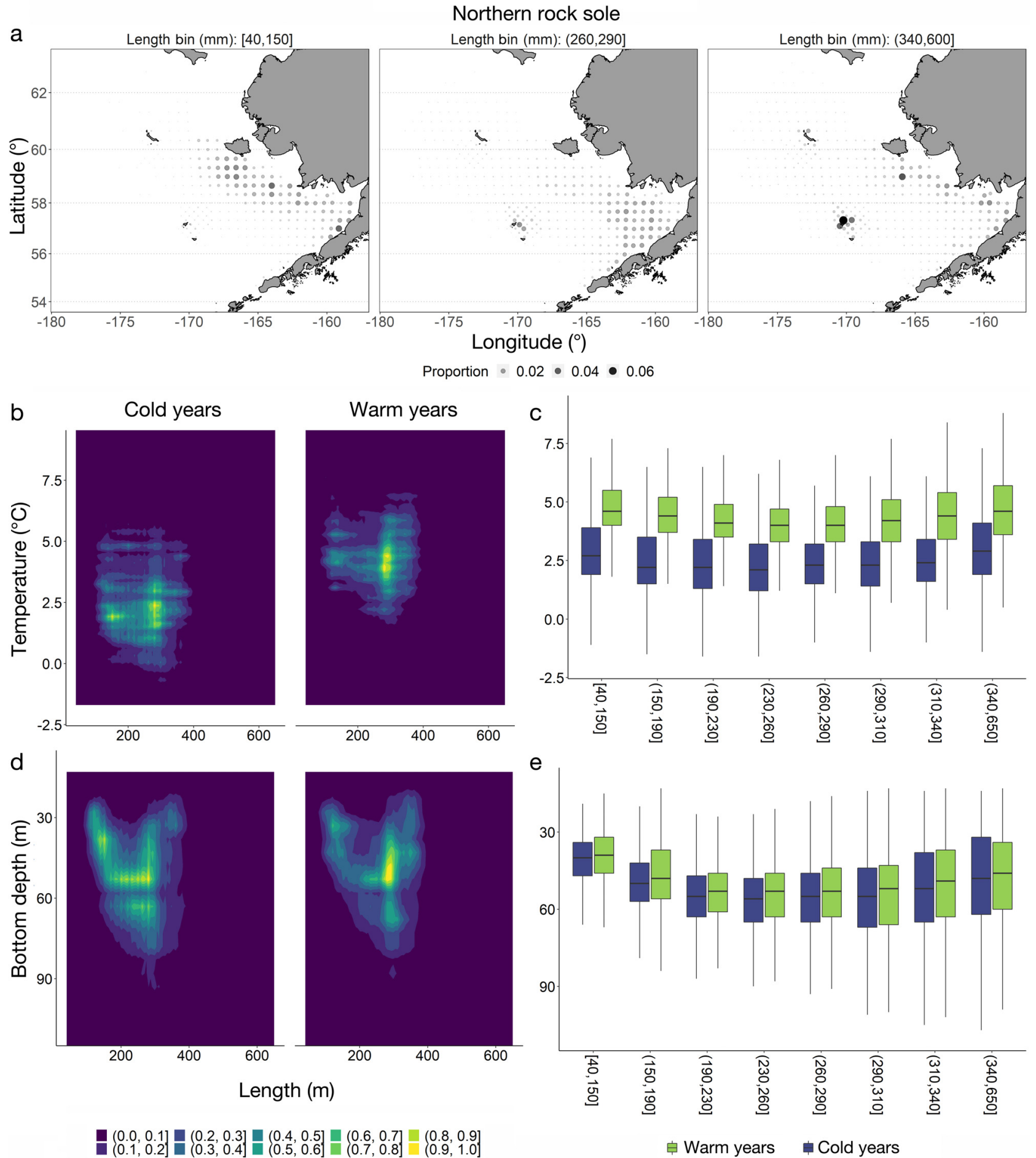

Fig. 2. (a) Spatial distribution of small (40-150 mm, left), medium (260-290 mm, center), and large (340-600 mm, right) northern rock sole Lepidopsetta polyxystra across all years (2000-2018). Grey circles: total number caught at a sample site as a proportion of the total number in the entire space. (b,c) Distribution by temperature for warm and cold years for different size categories. Image depicts the density of fish of a given length at a given depth. Larger values indicate more fish of that size at that depth; all values are normalized to the highest observed density of fish (value of 1). Boxes depict the $25^{\text {th }}-75^{\text {th }}$ percentiles with an additional central line for median; whiskers extend to the most extreme nonoutlier points, defined as within 1.5 times the interquartile range from either quartile. (d,e) Same as (b) and (c), but for bottom depth 


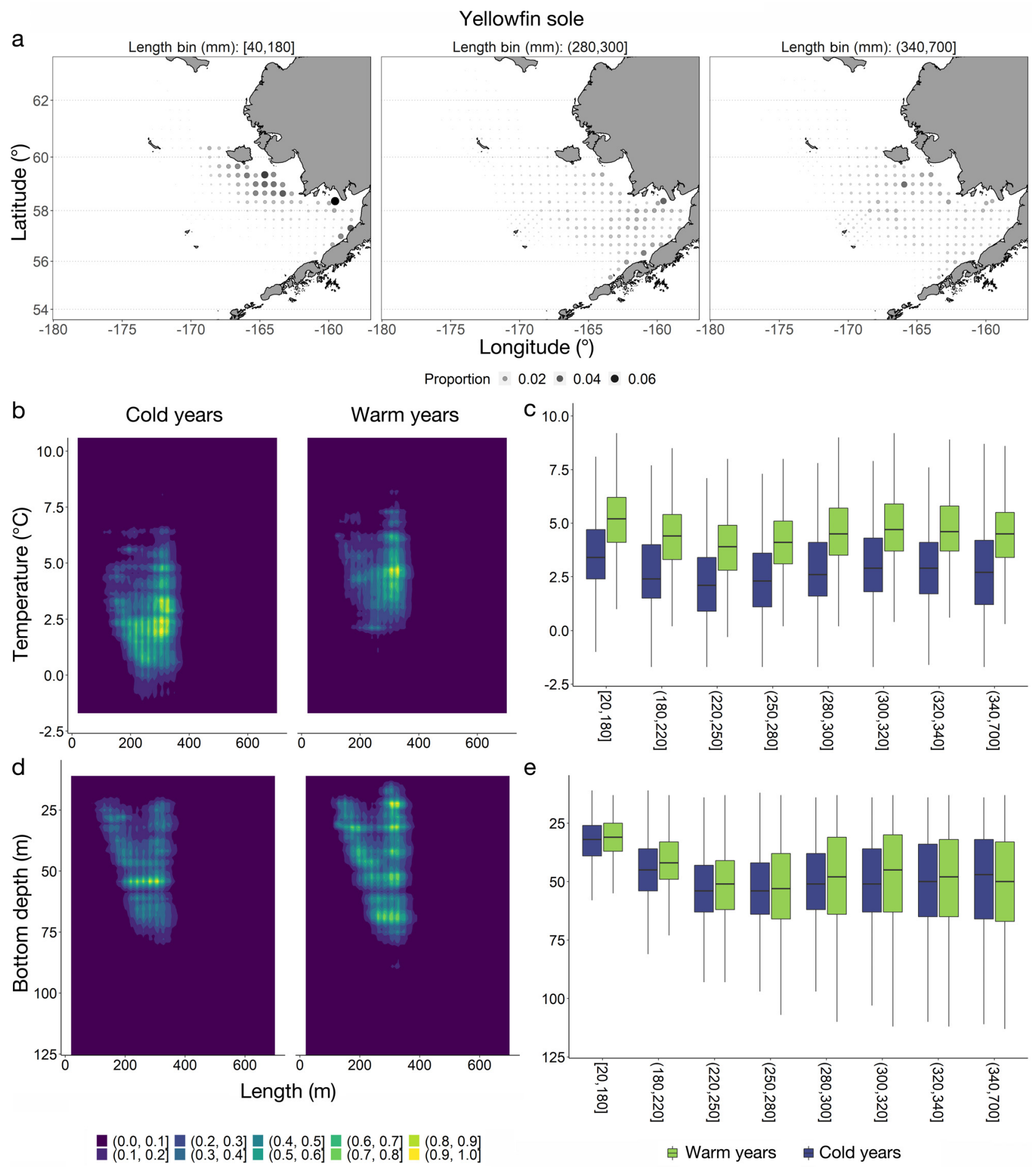

Fig. 3. Same as Fig. 2, but for small (40-180 mm), medium (280-300 mm), and large (340-700 mm) yellow sole Limanda aspera

from $30 \mathrm{~m}$ for smaller individuals to $70 \mathrm{~m}$ for the largest adult stages (450-720 mm). Unlike other species, these depth distribution patterns are influenced by water temperature, with a movement to deeper areas during warm years. The average variation in temperature exposure between warm and cold years can reach values of $2.0-2.5^{\circ} \mathrm{C}$ for the larger size groups (Fig. 4).

Flathead sole (Fig. 5) is abundant in the outer shelf between 100-200 m depth. Distinctly, flathead sole 

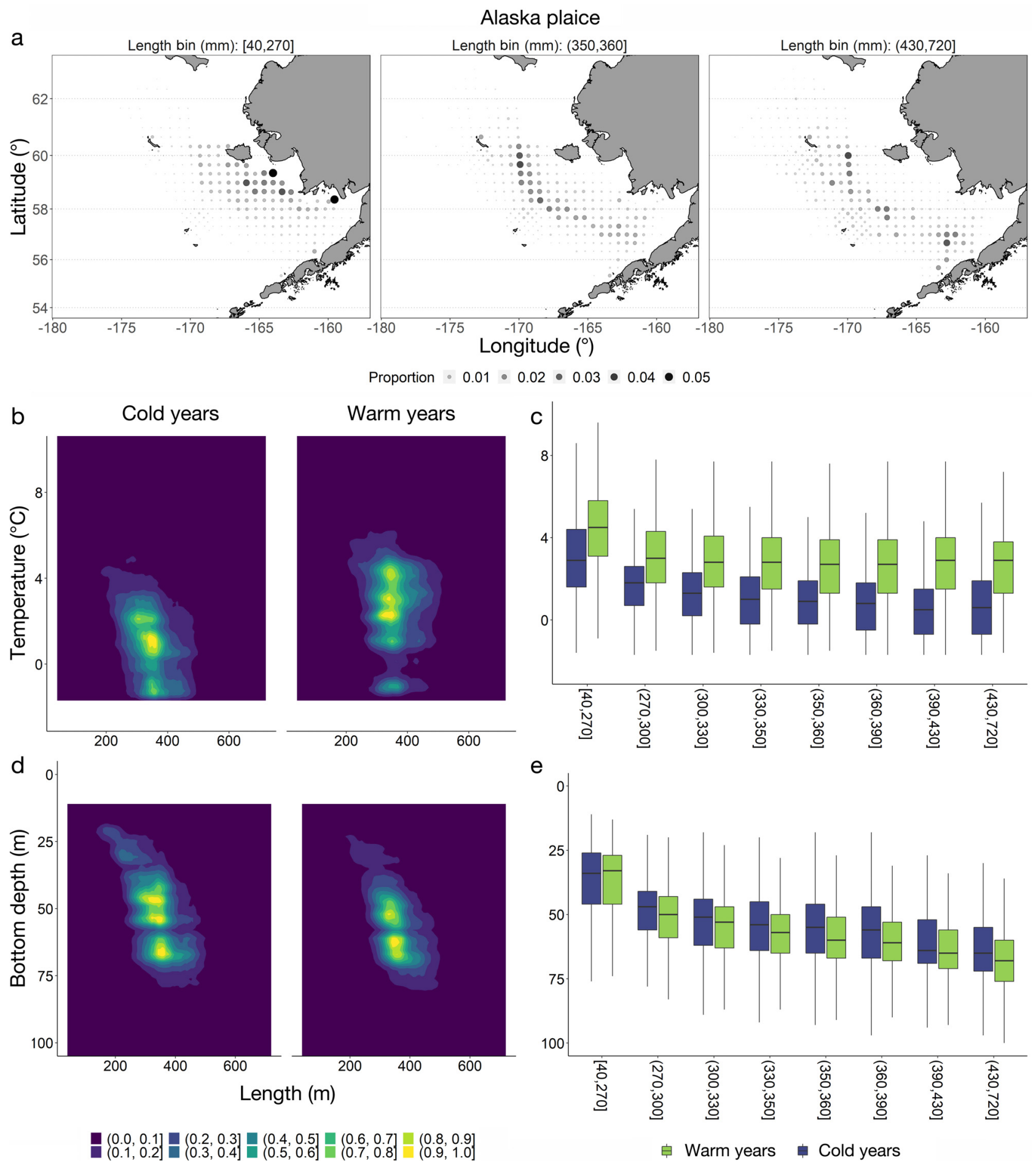

Fig. 4. Same as Fig. 2, but for small (40-270 mm), medium (350-360 mm), and large (430-720 mm) Alaska plaice Pleuronectes quadrituberculatus

depth distribution remains fairly constant throughout juvenile and adult ontogeny, with a slight movement of larger individuals toward shallower portions of the outer shelf. Their average depth distribution is concentrated around $120 \mathrm{~m}$ until individuals are $300 \mathrm{~mm}$ in length, at which point the larger and older individuals (300-630 $\mathrm{mm}$ in length) progressively move toward $80-100 \mathrm{~m}$ depth. Flathead sole individuals experience limited thermal changes between cold and warm years, averaging about $1.0^{\circ} \mathrm{C}$. 
Flathead sole

a Length bin $(\mathrm{mm}):[30,180]$

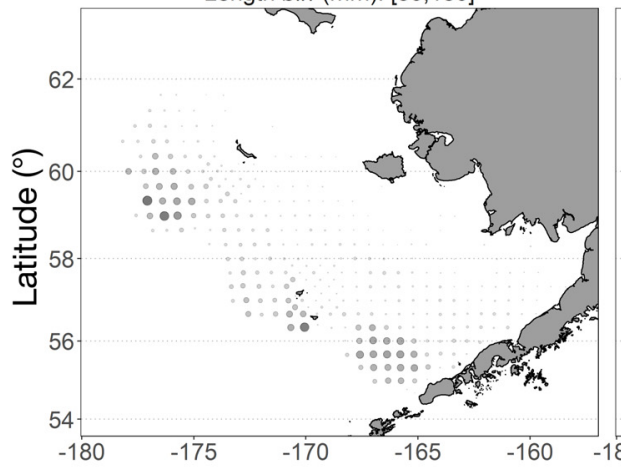

Length bin (mm): $(300,330]$
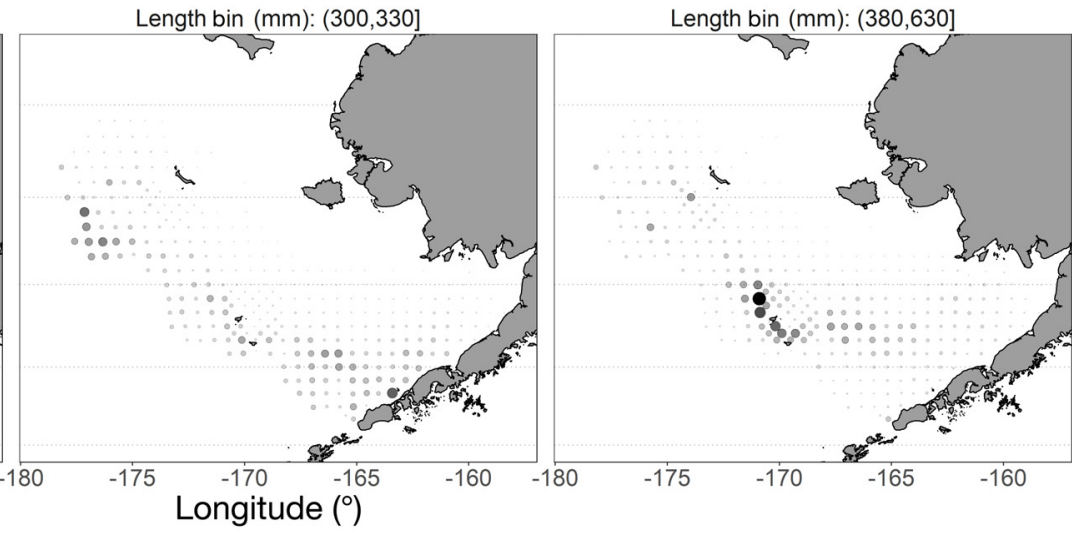

Proportion $\cdot 0.02 \cdot 0.04 \cdot 0.06$
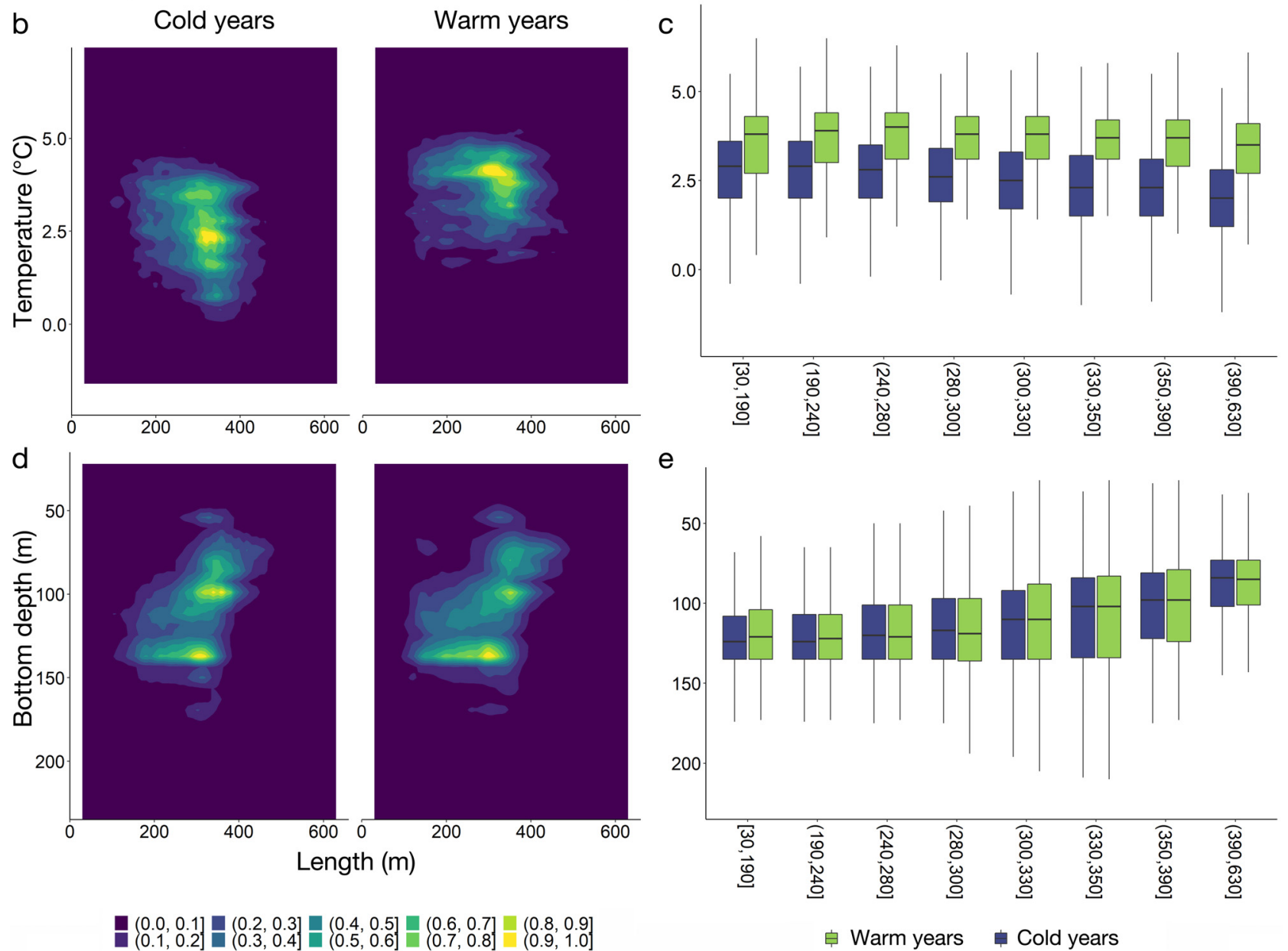

Fig. 5. Same as Fig. 2, but for small (30-180 mm), medium (300-330 mm), and large (380-630 mm) flathead sole Hippoglossoides elassodon

During years with marine heatwaves, the 4 species are exposed to markedly increased temperatures (Figs. S5-S8). For example, the smaller juvenile stages of northern rock sole experience an average change of water temperature of about $4-5^{\circ} \mathrm{C}$. Smaller and younger stages of yellowfin sole (Fig. S6) and Alaska plaice (Fig. S7) experience an increase of about $3-4^{\circ} \mathrm{C}$. Larger flathead sole (Fig. S8) experience higher water temperatures during heatwave years than during cold years. 


\section{DISCUSSION}

Species adaptability to climate change is a multipronged process that involves behavioral, physiological, and genetic responses (Visser 2008, Donelson et al. 2019). For marine fish, behavioral responses can occur when individuals move from less suitable toward more suitable areas. The rate at which these responses occur varies not only across species and marine systems (Cheung et al. 2009) but also over life history stages (Ciannelli et al. 2022). During ontogenetic development, marine fish species occupy different habitats and exhibit different vulnerabilities to climate change (Petitgas et al. 2013). For example, flatfish species that complete their life cycle on the shelf typically move from shallow coastal habitats during early life stages toward deeper habitats as individuals age and mature (Gibson et al. 2002). Our study demonstrates that flatfish stages inhabiting nearshore areas are exposed to double jeopardy from climate change. First, these stages are exposed to higher seasonal variability than those occupying deeper water. Second, their limited ability to move deeper when temperatures increase makes them more vulnerable to climate change.

While shallow water species/stages are likely physiologically adapted to large changes in temperature, the limits of their adaptability will be tested when the seasonal envelope of exposure exceeds their thermal optimum. For example, in the BS, the thermal optimum for juvenile rock sole is $\sim 13^{\circ} \mathrm{C}$, and survival starts to rapidly decline beyond that threshold (Ryer et al. 2012). The average temperature of the BS inner shelf habitats in 2070-2100 is expected to surpass $13^{\circ} \mathrm{C}$ for stretches of $1 \mathrm{mo}$ or longer. Other inner shelf species such as yellowfin sole and Alaska plaice that have a lower thermal optimum and higher thermal sensitivity than rock sole (T. Hurst pers. comm.) are likely to be more vulnerable to extreme heat waves and continuous warming over the next few decades.

The BS shelf is physically and biologically heterogeneous, hosting a variety of habitats and species assemblages, mostly organized along bathymetry and temperature gradients (Baker \& Hollowed 2014, Sigler et al. 2017). During summer, the bottom temperatures of the middle and outer shelf are less variable than that of the inner shelf. During late summer and fall, bottom temperature becomes more variable offshore. In general, offshore and deeper habitats are exposed to lower seasonal temperature variability during summer but greater interannual variability compared to shallower habitats of the BS. However, the maximum temperatures of the inner shelf are projected to increase beyond the optimal temperatures for growth of stenotherm species of Arctic and sub-Arctic origins, while middle and outer shelf temperatures will continue to remain below these optimal temperatures. Therefore, we expect that species and stages that reside inshore and that cannot move to other habitats are likely to be more vulnerable to climate change. Apart from flathead sole, all species examined in this study spend their early life stage in some portion of the BS inner shelf, and yellowfin sole early stages are almost exclusively found in shallow nearshore habitats. Flathead sole stands apart from all other species: they live in deeper and less thermally exposed habitats and move to shallower regions as they grow. This is potentially a good strategy to cope with increasing water temperatures.

A species' sensitivity to an environmental variable is proportional to the slope of the relationship between that variable and a particular trait (reaction norm; Visser 2008). It follows that the slope of the relationship between temperature and individual growth is a measure of the species' thermal sensitivity - with a more positive correlation indicating a higher sensitivity to temperature changes. Lower sensitivity to changes in temperature could be due to a variety of reasons, including physiological or behavioral responses or less exposure to thermal changes, if temperature is measured as an index over different habitats (e.g. at regional scales). Matta et al. (2010) found that otolith growth increments of Alaska plaice and yellowfin sole were more positively correlated with the summer water temperature of the eastern BS shelf area than that of northern rock sole, underscoring the thermal sensitivity and potential vulnerability to extreme high temperatures of the former 2 species. Northern rock sole was the least correlated, probably because of their ability to cope with higher temperature and their relatively higher habitat occupancy, especially during high abundance years, compared to the other 2 species examined.

Other variables, including the presence of infaunal and epibenthic prey, sediment size and lithology, predation, and fishing pressure are known to affect flatfish distribution. In previous studies conducted in the BS, several of these variables contributed to spatially anchoring species to specific habitats (McConnaughey \& Smith 2000, Spencer 2008). In terms of sediment type, inshore-oriented species occur within a mixture of sand and gravel, while offshore species are associated with fine sand and mud (Spencer 2008). Organic content and sediment size are correlated with higher trophic level community composition and abundance in benthic habitats 
(Grebmeier et al. 1989), and bathymetry is negatively correlated with sediment size. Not surprisingly, most of the shelf flatfish species in the BS have a strong affinity with depth (Swartzman et al. 1992). Spencer (2008) examined changes in distribution of several flatfish species, including the 4 studied here, in relation to the BS cold pool extent. They found that among 6 flatfish species examined, distribution shifts in the southeast region of the shelf were only correlated to the extent of the cold pool in flathead sole and northern rock sole. Bartolino et al. (2011) found that yellowfin sole juvenile stages shift their distribution in relation to water temperature, but to a lesser extent than adult individuals. In a follow-up study (Bartolino et al. 2012), the authors examined the effect of commercial harvest and found evidence of local depletion. Results from other systems confirm that fishing, in addition to temperature, is an important driver of fish distribution (Ciannelli et al. 2013, Frank et al. 2018). For example, Engelhard et al. (2011) found that the distribution of sole Solea solea in the North Sea was affected by fishing pressure. In addition, both sole and plaice Pleuronects platessa changed their distribution in relation to climate variability, albeit in opposite directions - sole moved southward and plaice moved northward.

There is mounting evidence of climate-driven shifts in species distributions and vulnerability in marine ecosystems worldwide (Dulvy et al. 2008, Pinsky et al. 2019, 2020, Gervais et al. 2021). Moreover, a growing number of studies are documenting the varied responses of marine organisms to climate change impacts owing to differences in physiological tolerances among taxonomic groups, types of performance measured, and life stages (Harvey et al. 2013, Twiname et al. 2019, Dahlke et al. 2020). However, our understanding of the vulnerability of marine species and the implications for their geographic distribution and broader ecosystem-level processes under a changing climate is still very limited. Here, we illustrated that within a large and oceanographically diverse region, such as the eastern BS shelf, exposure varies greatly across habitat types, and species sensitivity changes across ontogeny, underscoring the importance of both habitat-specific and size- or age-specific assessments. Results from this study can inform how we represent exposure and sensitivity in climate vulnerability assessments (e.g. Holsman et al. 2017). In previous assessments conducted for fish and invertebrate stocks in the BS, species were found to have limited exposures to climate change (Spencer et al. 2019); however, the authors only carried the projections to 2039. Our initial assessment also highlights the need for more comprehensive analyses of fish sensitivity across ontogeny, such as lab work to better understand physiological limits and thus how fish life stages will be impacted under future climate scenarios.

Acknowledgements. We are grateful to the crew and scientists of the Alaska Fisheries Science Center groundfish program, who have provided the long-term data used in the analyses of fish distributions. We thank George Hunt, Myron Peck, and 2 anonymous reviewers for the constructive feedback provided to earlier drafts of the manuscript. L.C. acknowledges funding from the North Pacific Research Board, project no. 1909A 'Phenology and geography of marine fish'.

\section{LITERATURE CITED}

Baker MR, Hollowed AB (2014) Delineating ecological regions in marine systems: integrating physical structure and community composition to inform spatial management in the eastern Bering Sea. Deep Sea Res II 109:215-240

Barbeaux SJ, Hollowed AB (2018) Ontogeny matters: climate variability and effects on fish distribution in the eastern Bering Sea. Fish Oceanogr 27:1-15

Bartolino V, Ciannelli L, Bacheler NM, Chan KS (2011) Ontogenetic and sex-specific differences in densitydependent habitat selection of a marine fish population. Ecology 92:189-200

*Bartolino V, Ciannelli L, Spencer P, Wilderbuer TK, Chan KS (2012) Scale-dependent detection of the effects of harvesting a marine fish population. Mar Ecol Prog Ser 444: 251-261

Carvalho KS, Smith TE, Wang S (2021) Bering Sea marine heatwaves: patterns, trends and connections with the Arctic. J Hydrol (Amst) 600:126462

Cheung WWL, Lam VWY, Sarmiento JL, Kearney K, Watson R, Pauly D (2009) Projecting global marine biodiversity impacts under climate change scenarios. Fish Fish 10: 235-251

* Ciannelli L, Fisher J, Skern-Mauritzen M, Hunsicker M, Hidalgo M, Frank K, Bailey K (2013) Theory, consequences and evidence of eroding population spatial structure in harvested marine fishes: a review. Mar Ecol Prog Ser 480:227-243

Ciannelli L, Neuheimer AB, Stige LC, Frank KT and others (2022) Ontogenetic spatial constraints of sub-arctic marine fish species. Fish Fish 23:342-357

Wahlke FT, Wohlrab S, Butzin M, Pörtner HO (2020) Thermal bottlenecks in the life cycle define climate vulnerability of fish. Science 369:65-70

*Donelson JM, Sunday JM, Figueira WF, Gaitán-Espitia JD and others (2019) Understanding interactions between plasticity, adaptation and range shifts in response to marine environmental change. Philos Trans R Soc B 374: 20180186

พ Dulvy NK, Rogers SI, Jennings S, Stelzenmller V, Dye SR, Skjoldal HR (2008) Climate change and deepening of the North Sea fish assemblage: a biotic indicator of warming seas. J Appl Ecol 45:1029-1039

Engelhard GH, Pinnegar JK, Kell LT, Rijnsdorp AD (2011) Nine decades of North Sea sole and plaice distribution. ICES J Mar Sci 68:1090-1104 
Frank KT, Petrie B, Leggett WC, Boyce DG (2018) Exploitation drives an ontogenetic-like deepening in marine fish. Proc Natl Acad Sci USA 115:6422-6427

Gervais CR, Champion C, Pecl GT (2021) Species on the move around the Australian coastline: a continentalscale review of climate-driven species redistribution in marine systems. Glob Change Biol 27:3200-3217

Gibson RN, Robb L, Wennhage H, Burrows MT (2002) Ontogenetic changes in depth distribution of juvenile flatfishes in relation to predation risk and temperature on a shallow-water nursery ground. Mar Ecol Prog Ser 229: 233-244

*Grebmeier JM, Feder HM, McRoy CP (1989) Pelagicbenthic coupling on the shelf of the northern Bering and Chukchi Seas. II. Benthic community structure. Mar Ecol Prog Ser 51:253-268

Haidvogel DB, Arango H, Budgell WP, Cornuelle BD and others (2008) Ocean forecasting in terrain-following coordinates: formulation and skill assessment of the Regional Ocean Modeling System. J Comput Phys 227: 3595-3624

* Harvey BP, Gwynn-Jones D, Moore PJ (2013) Meta-analysis reveals complex marine biological responses to the interactive effects of ocean acidification and warming. Ecol Evol 3:1016-1030

Holsman K, Samhouri J, Cook G, Hazen E and others (2017) An ecosystem-based approach to marine risk assessment. Ecosyst Health Sustain 3:e01256

IPCC (2014) Climate change 2014: impacts, adaptation, and vulnerability. Working Group II contribution to the Fifth Assessment Report of the Intergovernmental Panel on Climate Change. Cambridge University Press, New York, NY

Kearney K (2021) Temperature data from the Eastern Bering Sea continental shelf bottom trawl survey as used for hydrodynamic model validation and comparison. NOAA Tech Memo NMFS-AFSC-415

Kearney K, Hermann A, Cheng W, Ortiz I, Aydin K (2020) A coupled pelagic-benthic-sympagic biogeochemical model for the Bering Sea: documentation and validation of the BESTNPZ model (v2019.08.23) within a high-resolution regional ocean model. Geosci Model Dev 13:597-650

Llopiz J, Cowen R, Hauff M, Ji R and others (2014) Early life history and fisheries oceanography: new questions in a changing world. Oceanography 27:26-41

Matta ME, Black BA, Wilderbuer TK (2010) Climate-driven synchrony in otolith growth-increment chronologies for three Bering Sea flatfish species. Mar Ecol Prog Ser 413: $137-145$

*McConnaughey RA, Smith KR (2000) Associations between flatfish abundance and surficial sediments in the eastern Bering Sea. Can J Fish Aquat Sci 57:2410-2419

Mueter FJ, Litzow MA (2008) Sea ice retreat alters the biogeography of the Bering Sea continental shelf. Ecol Appl 18:309-320

Nichol DG, Kotwicki S, Wilderbuer TK, Lauth RR, Ianelli JN (2019) Availability of yellowfin sole Limanda aspera to the eastern Bering Sea trawl survey and its effect on estimates of survey biomass. Fish Res 211:319-330

* Petitgas P, Rijnsdorp AD, Dickey-Collas M, Engelhard GH and others (2013) Impacts of climate change on the complex life cycles of fish. Fish Oceanogr 22:121-139

Editorial responsibility: Myron Peck,

Den Burg, The Netherlands

Reviewed by: G. Hunt and 2 anonymous referees
Pinsky ML, Eikeset AM, McCauley DJ, Payne JL, Sunday JM (2019) Greater vulnerability to warming of marine versus terrestrial ectotherms. Nature 569:108-111

Pinsky ML, Selden RL, Kitchel ZJ (2020) Climate-driven shifts in marine species ranges: scaling from organisms to communities. Annu Rev Mar Sci 12:153-179

*Porter SM, Ciannelli L (2018) Effect of temperature on flathead sole (Hippoglossoides elassodon) spawning in the southeastern Bering Sea during warm and cold years. J Sea Res 141:26-36

Ryer CH, Laurel BJ, Stoner AW (2010) Testing the shallow water refuge hypothesis in flatfish nurseries. Mar Ecol Prog Ser 415:275-282

Ryer CH, Boersma KS, Hurst TP (2012) Growth and distributional correlates of behavior in three co-occurring juvenile flatfishes. Mar Ecol Prog Ser 460:183-193

* Shchepetkin AF, McWilliams JC (2005) The regional oceanic modeling system (ROMS): a split-explicit, freesurface, topography-following-coordinate oceanic model. Ocean Model 9:347-404

Sigler MF, Mueter FJ, Bluhm BA, Busby M and others (2017) Late summer zoogeography of the northern Bering and Chukchi seas. Deep Sea Res II 135:168-189

* Spencer PD (2008) Density-independent and densitydependent factors affecting temporal changes in spatial distributions of eastern Bering Sea flatfish. Fish Oceanogr 17:396-410

Spencer PD, Hollowed AB, Sigler MF, Hermann AJ, Nelson MW (2019) Trait-based climate vulnerability assessments in data-rich systems: an application to eastern Bering Sea fish and invertebrate stocks. Glob Change Biol 25:3954-3971

Stabeno PJ, Bond NA, Kachel NB, Salo SA, Schumacher JD (2001) On the temporal variability of the physical environment over the south-eastern Bering Sea: Bering Sea physical conditions. Fish Oceanogr 10:81-98

Stabeno PJ, Kachel NB, Moore SE, Napp JM, Sigler M, Yamaguchi A, Zerbini AN (2012) Comparison of warm and cold years on the southeastern Bering Sea shelf and some implications for the ecosystem. Deep Sea Res II 65-70:31-45

* Stabeno PJ, Duffy-Anderson JT, Eisner LB, Farley EV, Heintz RA, Mordy CW (2017) Return of warm conditions in the southeastern Bering Sea: physics to fluorescence. PLOS ONE 12:e0185464

* Stevenson DE, Lauth RR (2019) Bottom trawl surveys in the northern Bering Sea indicate recent shifts in the distribution of marine species. Polar Biol 42:407-421

* Swartzman G, Huang C, Kaluzny S (1992) Spatial analysis of Bering Sea groundfish survey data using generalized additive models. Can J Fish Aquat Sci 49:1366-1378

* Twiname S, Fitzgibbon QP, Hobday AJ, Carter CG, Pecl GT (2019) Multiple measures of thermal performance of early stage eastern rock lobster in a fast-warming ocean region. Mar Ecol Prog Ser 624:1-11

Visser ME (2008) Keeping up with a warming world; assessing the rate of adaptation to climate change. Proc R Soc B 275:649-659

Wilderbuer TK, Walters GE, Bakkala RG (1992) Yellowfin sole, Pleuronectes asper, of the Eastern Bering Sea: biological characteristics, history of exploitation, and management. Mar Fish Rev 54:1-18

Submitted: August 11, 2021

Accepted: December 10, 2021

Proofs received from author(s): February 11, 2022 